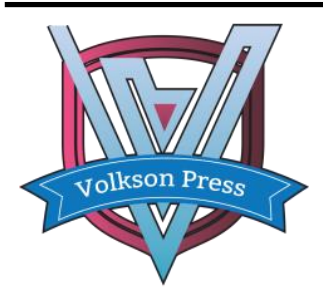

Contents List available at VOLKSON PRESS

Engineering \& Technology Innovations (ETI)

DOI : http://doi.org/10.26480/iceti.01.2017.42.44

\title{
SPECTROPHOTOMETRIC METHOD FOR THE DETERMINATION OF IRON SPECIES IN THE PRESENCE OF FERRIC IRON
}

\author{
Feifei Fana, Xiaoyun Guan' ${ }^{b}$, Yitong Lic, Jian Zhu ${ }^{\text {** }}$ \\ ${ }^{a}$ Guizhou Institute of Soil and Fertilizer, Xiaohe District, Guiyang, 550006, P. R. China \\ ${ }^{b}$ School-Enterprise Office of Yibin Vocation and Technical College, Cuiping District,Yibin, 644003, P. R. China \\ c College of Resource and Environmental Engineering, Guizhou University, Huaxi District, Guiyang, 550025, P. R. China *zhujian2009@126.com
}

This is an open access article distributed under the Creative Commons Attribution License, which permits unrestricted use, distribution, and reproduction in any medium, provided the original work is properly cited

\section{ARTICLE DETAILS}

\section{Article History:}

Received 02 october 2017 Accepted 06 october 2017 Available online 11 october 2017

Keywords:

\section{ABSTRACT}

Iron

Spectrophotometric method, Fluorine ion, Masking action, Storage condition.
The high concentration of ferric $\left(\mathrm{Fe}^{3+}\right)$ in sample has interference on the determination of ferrous( $\left.\mathrm{Fe}^{2+}\right)$ concentration by spectrophotometric method which 1, 10-phenanthroline is used to as chromogenic agent. Appropriate concentration of fluorine ion $\left(\mathrm{F}^{-}\right)$can complex $\mathrm{Fe}^{3+}$ to eliminate interferences which the $\mathrm{F}^{-}$-concentration is 13.3 time greater than that of $\mathrm{Fe}^{3+}$. The temperature and light do not affect the masking action of $\mathrm{F}$ - Low temperature and dark conditions favour the stability of chromophoric complex. This method is suitable for determination iron species in the presence of high concentration of $\mathrm{Fe}^{3+}$ in sample.

\section{INTRODUCTION}

Acid mine drainage (AMD) is caused by oxidation of sulfide minerals exposed to atmospheric oxygen. It distributes widely around the world, like USA [1], South Africa [2], Australia [3], Ireland [4] and China [5]. AMD is characterized by the low $\mathrm{pH}$ values $[1,6]$, the high iron concentrations and various heavy metal (such as $\mathrm{As}, \mathrm{Hg}, \mathrm{Sb}$ ) [7-8]. Iron species and content can affect transport and transformation of heavy metal. So, the determination of iron species concentrations is practical important in investigation of heavy metal.

The spectrophotometric methods have been commonly used for the analysis of iron content such as 2,2'-bipyridyl and 2,2',2"-terpyridyl4,7diphenly-lmethod [9], 4,7-diphenyl-1,10-phenanthroline method [10], ferrozine method [11] and 1, 10-phenanthroline method [12]. 1, 10phenanthroline method has been published and implemented as standard specifications of Ministry of Environmental Protection of the People's Republic of China due to its high sensitivity. The concentrations of $\mathrm{Fe}^{2+}$ and $\mathrm{Fe}^{3+}$ in AMD are very high, which reaches several hundreds and even thousands of $\mathrm{mg} / \mathrm{L}$. The high concentration $\mathrm{Fe}^{3+}$ affect analysis of $\mathrm{Fe}^{2+}$ in the process of spectrophotometric method using 1,10-phenanthroline, so we need a method to mask the effect of $\mathrm{Fe}^{3+}$. The $\mathrm{F}^{-}$react with $\mathrm{Fe}^{3+}$ to form ferric fluoride [11] which do not react with 1,10-phenanthroline, so $\mathrm{F}^{-}$was used to a complexing agent to modify the 1,10- phenanthroline method. The study about method of application of $\mathrm{F}^{-}$and storage conditions of chromophoric complexes are few.

The objectives of this study were to investigate affects of $\mathrm{Fe}^{3+}$ and choice of suitable reagent to mask the effect of $\mathrm{Fe}^{3+}$, assess effect of reaction temperature, light and time. At last, the solutions after chromogenesis were stored under different conditions to evaluate the stability of chromophoric complex.

\section{Materials and methods}

\subsection{Chemicals}

Ferrous sulfate (99.9\%), ferric chloride (99.9\%), sodium fluoride (99.9\%), ammonium acetate (99.9\%), acetic acid (99.9\%), 1, 10-phenanthroline
(99.9\%) were purchased from Sinopharm Chemical Regent Co. Ltd, China. The deionized water prepared by a Milli-Q water purification device (Millipore) was used in all experiments.

\subsection{Batch experiments}

Different volumes $400 \mathrm{mg} / \mathrm{L} \mathrm{Fe}^{3+}$ solution were added to $2 \mathrm{mg} / \mathrm{L} \mathrm{Fe}^{2+}$ solution respectively to form different $\mathrm{Fe}^{3+}$ concentrations. The molar ratios of $\mathrm{Fe}^{3+}$ to $\mathrm{Fe}^{2+}$ respectively were $0,0.1,0.5,1,2,4,8,16$. These samples were used to assess the interferences of $\mathrm{Fe}^{3+}$ on measurement of $\mathrm{Fe}^{2+}$.

To get appropriate concentration of $\mathrm{F}^{-}$to mask $\mathrm{Fe}^{3+}$, we added different concentrations $\mathrm{F}^{-}$into solutions which contain $2 \mathrm{mg} / \mathrm{L} \mathrm{Fe}^{2+}$ and $8 \mathrm{mg} / \mathrm{L}$ $\mathrm{Fe}^{3+}$ to make molar ratio of $\mathrm{F}^{-}$to $\mathrm{Fe}^{3+}$ respectively be $0,1,2,4,6,8,12,18$, 36 and 72. To evaluate the influence of temperature on masking action of $\mathrm{F}$-, we made solution temperature to be 5,15 and $30^{\circ} \mathrm{C}$. To examine stability of chromophoric complexes, solutions were stored in different temperature and light conditions.

\subsection{Chemical analysis}

The concentration of $\mathrm{Fe}^{2+}$ was measured by the 1,10-phenanthroline analytical method at $510 \mathrm{~nm}$ using a UV-vis spectrophotometer 12]. Total iron concentrations were measured through reduction of $\mathrm{Fe}^{3+}$ to $\mathrm{Fe}^{2+}$ by hydroxylamine- $\mathrm{HCl}$. The concentration of $\mathrm{Fe}^{3+}$ was calculated as the difference in concentrations between total iron and $\mathrm{Fe}^{2+}$.

\section{Results and discussion}

3.1 Analysis of the error of determination of $\mathrm{Fe}^{2+}$ in presence of $\mathrm{Fe}^{3+}$ 


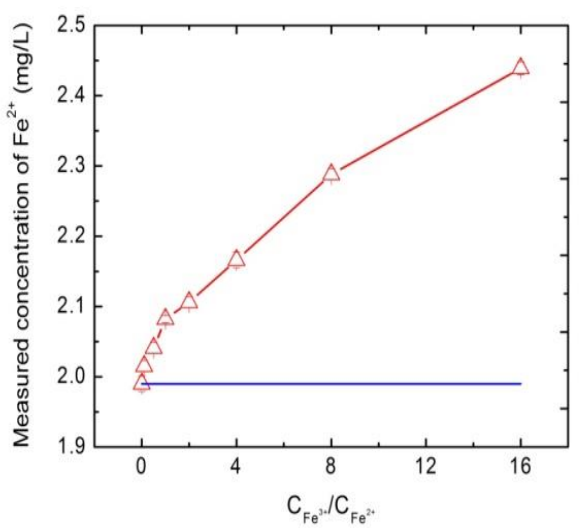

Fig. 1 Interference of $\mathrm{Fe}^{3+}$ on measurement concentration of $\mathrm{Fe}^{2+}$. $\mathrm{C}$ $\mathrm{Fe}^{3+} / \mathrm{C}_{\mathrm{Fe}^{2+}}{ }^{2+}$ was molar concentration ratio. Expermentas conditions: $2 \mathrm{mg} / \mathrm{L}$ $\mathrm{Fe}^{2+}$ and different concentration of $\mathrm{Fe}^{3+}$.

To analyze the effect of $\mathrm{Fe}^{3+}$ on measurement of $\mathrm{Fe}^{2+}$, different concentrations of $\mathrm{Fe}^{3+}$ were added to $2 \mathrm{mg} / \mathrm{L} \mathrm{Fe}^{2+}$ solution. The resulting absorbance $(510 \mathrm{~nm})$ increased with the concentrations of $\mathrm{Fe}^{3+}$, as shown in Fig. 1. The error of result reached to $22.6 \%$ when the concentration of $\mathrm{Fe}^{3+}$ was 16 times than that of $\mathrm{Fe}^{2+}$ which is common in AMD. So, high concentration of $\mathrm{Fe}^{3+}$ obviously affect measurement of $\mathrm{Fe}^{2+}$.

\subsection{Determination of F- dosage}

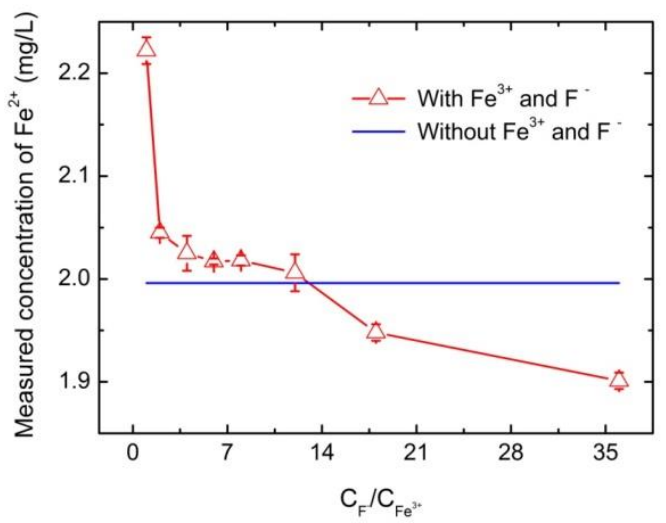

Fig. 2 Effect of dosage of $\mathrm{F}^{-}$on the determination of $\mathrm{Fe}^{2+}$ in the presence of $\mathrm{Fe}^{3+}$. Expermental conditions: $2 \mathrm{mg} / \mathrm{L} \mathrm{Fe}^{2+}$ and $8 \mathrm{mg} / \mathrm{L} \mathrm{Fe}^{3+}, \mathrm{C}_{\mathrm{F}} / \mathrm{C}_{\mathrm{Fe}}{ }^{3+}$ was molar concentration ratio.

The F- react with $\mathrm{Fe}^{3+}$ to form ferric fluoride [11] to make $\mathrm{Fe}^{3+}$ do not react with 1,10-phenanthroline, so F- was selected as the complexing agent to modify the 1,10-phenanthroline method. The effect of $\mathrm{F}^{-}$on the determination of $\mathrm{Fe}^{2+}$ in the presence of $\mathrm{Fe}^{3+}$ was shown in Fig. 2, which 2 $\mathrm{mg} / \mathrm{L} \mathrm{Fe}^{2+}$ and $8 \mathrm{mg} / \mathrm{L} \mathrm{Fe}^{3+}$ were in solution. It should be noted that absorbance of sample after chromogenesis decreased with the increase of concentrations of F- (Fig. 2). In combination with effect of F- dosages, we concluded that there was an optimal dosage for masking $\mathrm{Fe}^{3+}$ which the concentration of $\mathrm{F}^{-}$was 13.3 time than that of $\mathrm{Fe}^{3+}$ (Fig. 2). So, the amount of $\mathrm{F}$ - required depends on the expected $\mathrm{Fe}^{3+}$ concentration in the sample. With less or more dosage of $\mathrm{F}^{-}$, the masking effect of $\mathrm{F}^{-}$was not best.

\subsection{Effect of temperature on reaction}

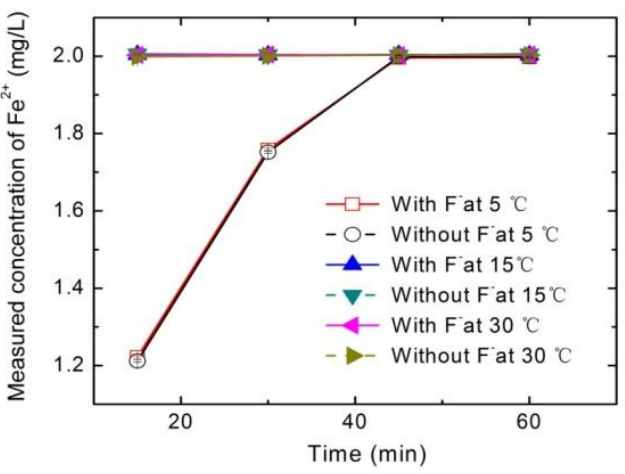

Fig.3 Effect of temperature on the determination of $\mathrm{Fe}^{2+}$ in the presence of $\mathrm{Fe}^{3+}$. Expermental conditions: $2 \mathrm{mg} / \mathrm{L} \mathrm{Fe}^{2+}, 8 \mathrm{mg} / \mathrm{L} \mathrm{Fe}^{3+}$ and with or without of $36.1 \mathrm{mg} / \mathrm{L} \mathrm{F}^{-}$under room light illumination.

Because temperature affect chemical reaction ratio, we evaluated the influence of temperature on F- masking action. The sample which contain $2 \mathrm{mg} / \mathrm{L} \mathrm{Fe}^{2+}, 8 \mathrm{mg} / \mathrm{L} \mathrm{Fe}^{3+}$ and with or without addition of $\mathrm{F}^{-}$were respectively stored at 5,15 and $30^{\circ} \mathrm{C}$. The Fig. 3 showed that temperature did not effect masking action of $\mathrm{F}$; , but affect significantly chromogenic reaction ratio at $5-30{ }^{\circ} \mathrm{C}$. The chromogenic reaction of $\mathrm{Fe}^{2+}$ has been finished within 15 minute, and the complexes from the reaction of $\mathrm{Fe}^{2+}$ with 1,10- phenanthroline keep stable in 1 hour at $15-30{ }^{\circ} \mathrm{C}$. The chromogenic reaction of $\mathrm{Fe}^{2+}$ has been finished within 45 minute at $5{ }^{\circ} \mathrm{C}$. This suggested that chromogenic reaction of $\mathrm{Fe}^{2+}$ need more time in lower temperature.

\subsection{Effect of storage condition}

To further evaluate the stablity of chromophoric complexes, the solution with and without $\mathrm{F}^{-}$after chromogenesis were stored different conditions which including room light illumination at $25^{\circ} \mathrm{C}$, dark at $25^{\circ} \mathrm{C}$ and dark at $5{ }^{\circ} \mathrm{C}$. The temperature and light did not affect the masking action, but affect the stability of chromophoric complexes (Fig. 4). The effect of temperature on breaking complex was greater than the light (Fig. 4). The chromophoric complexes were stable under dark condition and $5{ }^{\circ} \mathrm{C}$ within $12 \mathrm{~h}$.

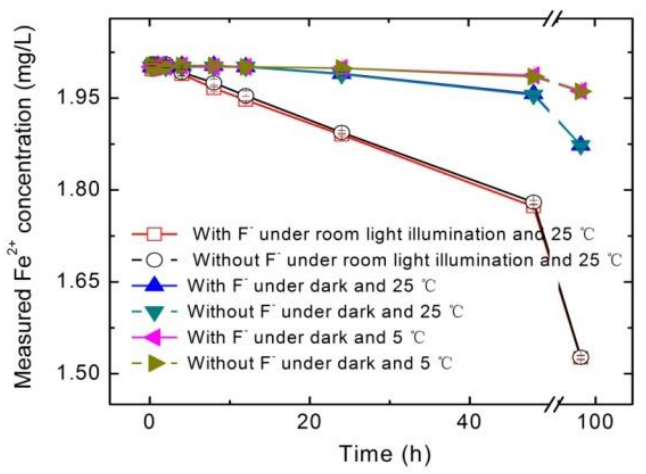

Fig. 4 Effect of light and temperature on chromophoric complexes. Expermental conditions: $2 \mathrm{mg} / \mathrm{L} \mathrm{Fe}^{2+}, 8 \mathrm{mg} / \mathrm{L} \mathrm{Fe}^{3+}$ and with or without of $36.1 \mathrm{mg} / \mathrm{L} \mathrm{F}$ - after chromogenesis.

\section{Conclusion}

The high concentration $\mathrm{Fe}^{3+}$ in water sample affect analysis of $\mathrm{Fe}^{2+}$ concentration in the process of spectrophotometric method by 1,10 phenanthroline method. Appropriate concentration of $\mathrm{F}^{-}$can mask the effect of $\mathrm{Fe}^{3+}$ which the $\mathrm{F}$ - concentration is 13.3 time greater than that of $\mathrm{Fe}^{3+}$. The temperature and light do not affect the masking action of $\mathrm{F}$. Low temperature and dark conditions favour the stability of chromophoric complex. This method is suitable for determination of concentration of iron species in the presence of high concentration of $\mathrm{Fe}^{3+}$ in sample.

\section{Acknowledgments}

This work was supported by the Science and Technology Foundation of Guizhou Provice (No. J- LKN[2013]27).

\section{References}

[1] Nordstrom, D.K., Alpers, C.N., Ptacek, C.J., Blowes, D.W., 2000. Negative ph and extremely acidic mine waters from iron mountain, california. Environ. Sci. Technol. 34, 254-258.

[2] Tutu, H., McCarthy, T.S., Cukrowska, E., 2008. The chemical characteristics of acid mine drainage with particular reference to sources, distribution and remediation: The Witwatersrand Basin, South Africa as a case study. Applied Geochemistry 23, 3666-3684.

[3] Webb, J.A., Sasowsky, I.D., 1994. The interaction of acid mine drainage with a carbonate terrane: evidence from the Obey River, north-central Tennessee. Journal of Hydrology 161, 327-346.

[4] Gray, N.F., 1998. Acid mine drainage composition and the implications for its impact on lotic systems. Water Research 32, 2122-2134.

[5] Wu, P., Tang, C., Liu, C., Zhu, L., Pei, T., Feng, L., 2009. Geochemical 
distribution and removal of $\mathrm{As}, \mathrm{Fe}, \mathrm{Mn}$ and $\mathrm{Al}$ in a surface water system affected by acid mine drainage at a coalfield in Southwestern China. Environmental Geology 57, 1457-1467.

[6] D. W. Blowes , C.J.P.a.C.G.W., 2003. The geochemistry of acid mine drainage, in: Rudnick, R.L. (Ed.), Treatise on Geochemistry. Elsevier Ltd, pp. 149-204.

[7] Arnold, T., Baumann, N., Krawczyk-Baersch, E., Brockmann, S., Zimmermann, U., Jenk, U., Weiss, S., 2011. Identification of the uranium speciation in an underground acid mine drainage environment. Geochim. Cosmochim. Acta 75, 2200-2212.

[8] Iakovleva, E., Makila, E., Salonen, J., Sitarz, M., Wang, S., Sillanpaa, M., 2015. Acid mine drainage (AMD) treatment: Neutralization and toxic elements removal with unmodified and modified limestone. Ecol. Eng. 81, 30-40.
[9] Moss, M.L., Mellon, M.G., 1942. Colorimetric Determination of Iron with 2, 2'-Bipyridyl and with 2, 2', 2'-Terpyridyl. Industrial \& Engineering Chemistry Analytical Edition 14, 862-865.

[10] Clark, L.J., 1962. Iron(II) Determination in the Presence of Iron(III) Using 4,7-Diphenyl-1,10-phenanthroline. Analytical Chemistry 34, 348352.

[11] Herrera, L., Ruiz, P., Aguillon, J.C., Fehrmann, A., 1989. A new spectrophotometric method for the determination of ferrous iron in the presence of ferric iron. Journal of Chemical Technology and Biotechnology $44,171-181$.

[12] Tamura, H., Goto, K., Yotsuyanagi, T., Nagayama, M., 1974. Spectrophotometric determination of iron (II) with 1, 10-phenanthroline in the presence of large amounts of iron (III). Talanta 21, 314-318. 